\title{
TUS OJOS EN LA LITERATURA: ARTICULANDO LÍNGUA E LITERATURA ESPANHOLA SOB O OLHAR DA COMPLEXIDADE
}

\author{
P.P.F COELHO ${ }^{1 *}$ \\ ${ }^{1}$ Centro Universitário Municipal de Franca - Uni-Facef, SP \\ priscilapenna.adv@gmail.com*
}

Submetido 03 /12/2018 - Aceito 26/12/2018

DOI: $10.15628 /$ holos.2018.8007

\section{RESUMO}

O objetivo da pesquisa é relatar e interpretar as vivências da articulação entre língua e literatura espanhola por meio de um projeto proposto às alunas do último ano de Letras/Espanhol do Centro Universitário Municipal de Franca (Uni-Facef). A pesquisa se fundamenta teoricamente na complexidade (MORIN, 2015), nos gêneros textuais (MARCUSHI, 2010;
BAKHTIN, 1997), e nos textos literários como recurso de aprendizagem de E/LE (SIOMIONI, 2017; VENTURI, 2014). O projeto possibilitou a articulação de língua e literatura espanhola e ofereceu às participantes a oportunidade de refletirem a presença de textos literários em suas futuras aulas de espanhol.

PALAVRAS-CHAVE: Língua espanhola, Literatura espanhola, Pensamento Complexo, Dinamicidade dos gêneros textuais

\section{TUS OJOS EN LA LITERATURA: ARTICULATING SPANISH LANGUAGE AND LITERATURE UNDER THE EYES OF COMPLEXITY}

\section{ABSTRACT}

The aim of this research is to report and interpret the experiences of the articulation between Spanish language and literature through a project proposed to the students of the last year of Languages / Spanish. The research is based theoretically on the complexity (MORIN, 2015), in the textual genres (MARCUSHI, 2010;
BAKHTIN, 1997), and in the literary texts as a learning resource of E/LE (SIOMIONI, 2017; VENTURI, 2014). The project enabled the articulation of Spanish language and literature and offered participants the opportunity to reflect the presence of literary texts in their future Spanish classes.

KEYWORDS: Spanish language; Spanish Literature; Complexity; Dynamicity of textual genres. 


\section{INTRODUÇÃO}

Como professora de língua e literatura espanhola no curso superior de Letras, sempre notei que os graduandos não visualizam a possibilidade do ensino da língua espanhola, considerando o texto literário como recurso de ensino.

Esta pesquisa teve origem a partir da inquietação acadêmica de desvendar ou tentar encontrar um caminho para formar professores que articulem língua e literatura espanhola como prática educativa. A tentativa é romper com os modelos educacionais fragmentados e reducionistas que insistem em estar presentes no contexto de formação de professores.

O presente artigo tem como objetivo relatar e interpretar as vivências de um projeto que buscou a articulação de língua e literatura espanhola. Por meio do projeto "Tus ojos en la literatura", realizado com o último ano do curso de Letras/Espanhol do Centro Universitário Municipal de Franca, na disciplina de Literatura Espanhola e Hispano-Americana, cinco alunas reescreveram e ressignificaram duas obras pertencentes à Literatura hispano falante de autores bem conhecidos mundialmente: Veinte poemas de amor y una canción desesperada, de Pablo Neruda, e La Gitanilla de Cervantes.

Na primeira seção do artigo, apresento uma reflexão sobre o gênero e sua ressignificação na contemporaneidade. Um dos objetivos do projeto proposto é ressignificar a fotonovela tradicional para a digital. Ressaltando que, neste presente artigo, a fotonovela considerada tradicional é impressa, em formato revista, vinculada nos anos 40 e 50 . Tal transposição de gênero possibilitou ao projeto a articulação de língua e literatura espanhola e ofereceu a possibilidade de as participantes do projeto refletirem sobre a presença das obras escolhidas em suas futuras aulas de língua espanhola.

Marcuschi (2011, p.18) explica que não devemos conceber os gêneros como modelos estanques e estruturas rígidas, mas como formas culturais e cognitivas de ação social, efetivadas de modo particular na linguagem, portanto é possível perceber a dinamicidade do gênero.

Continuando os estudos, na segunda seção, retrato o pensamento complexo como prática educativa. Segundo Morin (2011), é preciso romper com algumas barreiras e reconhecer a necessidade emergente de uma reforma de pensamento na educação, por isso o autor e o seu pensamento passam a ser uma grande referência e inspiração para que enfrentemos o reducionismo presente na educação e alcancemos as mudanças que são necessárias.

Ler é fundamental em nossa sociedade porque melhora nosso senso crítico, amplia vocabulário e nos torna mais articulados. Por isso, na terceira seção, defendo a importância de trabalhar com textos literários como processo de aprendizagem em língua espanhola. $O$ esforço para articular a leitura de textos literários em língua espanhola, em sala de aula, pode ser estimulante na aquisição de uma língua estrangeira. Por fim, na seção metodológica e de interpretação, relato como foi realizado o projeto e como se deu a articulação entre língua e 
literatura espanhola juntamente com as vivências e os relatos colhidos das alunas, mostrando o que o projeto proporcionou às alunas.

\section{DA FOTONOVELA TRADICIONAL À DIGITAL}

Sempre com o intuito de que o aluno realmente construa conhecimento, o professor recorre, descobre e redescobre diversas metodologias e ferramentas para que as utilize em suas aulas. Os estudantes são reflexos de um novo tempo, uma nova época, com um jeito diferente de ser, viver e pensar. O professor do Ensino Superior também está diante de novos desafios, principalmente, ao se propor contribuir para a transformação da sociedade atual, em uma sociedade mais ética e humana.

Os gêneros podem ser redescobertos e ressignificados devido a sua dinamicidade. Por isso, para este artigo, me apoio nas ideias de Luiz Antônio Marcuschi (2010), que esclarece que o estudo dos gêneros textuais é uma fértil área interdisciplinar, com atenção especial para o funcionamento da língua e para as atividades culturais e sociais.

O projeto proposto às alunas explora não só a dinamicidade do gênero, mas também a situacionalidade e sua historicidade, com o intuito de mostrar que eles não são classificáveis como formas puras, nem podem ser catalogados de maneira rígida.

Para Marcuschi (2010), não devemos conceber os gêneros como modelos estanques, com estruturas rígidas, mas devemos entendê-los como formas culturais e cognitivas de ação social corporificadas de modo particular na linguagem, como entidades dinâmicas. Claro que não podemos esquecer que os gêneros possuem uma identidade e, quando produzidos, nos condicionam a escolhas que não podem ser totalmente livres, nem aleatórias, seja sob o ponto de vista do léxico, do grau de formalidade ou da natureza dos temas.

A relação enunciativa é a base da escolha do gênero, portanto tema (tópico do discurso como um todo), plano composicional (estrutura formal) e estilo (leva em conta a forma individual de escrever; vocabulário, composição frasal e gramatical) levam à especificidade de cada esfera de comunicação. Essas três características estão totalmente relacionadas entre si, principalmente, devido a sua construção composicional. No entanto, Brait e Pistori (2012, p.373) nos lembram que não podemos entender o gênero do discurso reduzido somente a esses três elementos. O que se deve levar em conta e não deve ser esquecido é que tanto os textos de forma geral, quanto o conceito de gênero produzido pelo pensamento bakhtiniano são frutos de um contexto, de uma época, de uma maneira de conceber conhecimento, linguagem, relação homem-mundo.

No caso deste estudo, a relação entre a fotonovela impressa em papel, em formato revista, com seu estilo e forma composicional, e a fotonovela digital, realizada no programa Power Point, surge a partir daí. Segundo Marcuschi (2002, p.1), "não são muitos os gêneros emergentes nessa nova tecnologia, nem totalmente inéditos. Contudo, sequer se consolidaram e já provocam polêmicas quanto à natureza e proporção de seu impacto na linguagem e na vida". 
O gênero é essencialmente flexível e variável, tal como seu componente crucial, a linguagem. A fotonovela impressa em papel possui suas especificidades (tema, forma composicional e estilo), seu tempo e lugar histórico, porém, assim como a língua, variam também os gêneros. Segundo Marcuschi (2011, p.19), "os gêneros adaptam-se, renovam-se e multiplicamse". Por que então, não ressignificar a fotonovela?

Fotonovelas são novelas em quadrinhos que utilizam fotografias ao invés de desenhos, de forma a contar, sequencialmente, uma história. Tem como objetivo central, uma narrativa que utiliza em conjunto a fotografia e o texto verbal. Como nas histórias em quadrinhos desenhadas, cada quadrinho da sequência corresponde a uma cena da história, no caso, corresponde a uma fotografia acompanhada da mensagem textual. As publicações das fotonovelas antigas, impressas em papel, eram no formato de revistas, livretos ou de pequenos trechos editados em jornais e revistas. Algumas eram divididas em capítulos que, geralmente, tinham um desfecho próprio e criavam suspense e curiosidade no leitor, levando-o a comprar a continuação.

A proposta do projeto é observar os gêneros pelo seu lado dinâmico, processual, social, interativo, cognitivo, evitando a classificação e a postura estruturais. Marcuschi esclarece:

\footnotetext{
Os gêneros devem ser vistos na relação com as práticas sociais, os aspectos cognitivos, os interesses, as relações de poder, as tecnologias, as atividades discursivas e no interior da cultura. Eles mudam, fundem-se, misturam-se para manter sua identidade funcional com inovação organizacional. (MARCUSCHI, 2011, p. 19)
}

Com base em Marcuschi (2011), os gêneros são formações interativas, multimodalizadas e flexíveis de organização social e de produção de sentidos.

\section{O PENSAMENTO COMPLEXO COMO PRÁTICA EDUCATIVA NA FORMAÇÃO DOCENTE}

Com base em leituras realizadas, percebo que a forma educacional adotada pela maioria das escolas e universidades ainda insiste em ser linear, determinista e não consegue explicar as transformações que ocorrem de maneira acelerada na educação. Segundo Morin (2011), é preciso romper com algumas barreiras e reconhecer a necessidade emergente de uma reforma de pensamento.

A epistemologia da Complexidade é compreendida como um princípio articulador do pensamento integrador, que liga diferentes formas de pensar, permitindo a tessitura entre sujeito e objeto, ordem e desordem, estabilidade e movimento, professor e aluno, e todos os tecidos que conduzem os eventos, ações e interações da vida.

Segundo Morin (2011), há três princípios que norteiam este pensamento: dialógico (ressalta o diálogo entre opostos que não se contrariam, mas se complementam, como por exemplo, razão e emoção); recursivo (enfatiza a retroação a um ponto para refletir, desconstruir ou reconstruir um conhecimento retornando a um ponto à frente com outro olhar, eliminando a linearidade entre causa e efeito); e hologramático (reconhece a incompletude e o inacabado de qualquer conhecimento, destacando a relação entre o todo e as partes). Desenvolver a 
epistemologia da complexidade é fazer evoluir um pensamento que une, que articula, que liga/religa saberes e que não os fragmenta.

Segundo Almeida (2014), por meio do pensamento complexo, seremos capazes de rever antigas sabedorias e experimentar outros modos de conhecer a realidade. Complementando essa ideia, Moraes (2008), entende a complexidade como fator constitutivo da vida e pela qual se procura compreender a tessitura comum que há entre o sujeito e o objeto, o indivíduo e o contexto, o educador e o educando, o presencial e o virtual, a análise e a síntese, e tudo o que rege os acontecimentos, as interações e as retroações que constroem a realidade da existência humana.

Conforme Coelho (2017), é preciso contextualizar nossa realidade socioeducacional, como hoje ela se apresenta. É difícil, para nós professores, compreender o caos, a ordem fazendo parte da desordem, a incerteza, a não linearidade e o indeterminismo, presentes, cada vez mais, nos processos de construção de conhecimento nos ambientes educacionais. Estamos acostumados a trabalhar com certezas e verdades, com estabilidade e previsibilidade. A educação atual, a meu ver, transmite muitas informações sem contextualizá-las, não ensina e motiva o aluno a construir e articular o conhecimento.

É necessário que o professor de nível superior, formador de professores da atualidade, seja capaz de construir, desconstruir e reconstruir o conhecimento sempre que pertinente. Um docente que tenha sensibilidade para perceber, segundo Moraes (2010), os momentos em que algo precisa ser mudado, refletido ou reconstruído na prática cotidiana. O pensamento complexo surge como inspiração para amparar este artigo, pois tal epistemologia sugere que a formação docente seja pensada como um todo, de maneira integrada e articulada em relação aos diferentes processos e dimensões envolvidas.

Como formadora de professores, acredito que seja necessário compartilhar, com futuros professores, a ideia da urgência da mudança de pensamento. Busco maneiras de esclarecer aos meus alunos, como a educação tradicional, fragmentada, linear, superespecializada tem tornado o ser humano também fragmentado. No entanto, não basta somente lançar ideias, é preciso vivenciá-las. É necessário ação para concretizar de forma real a mudança de pensamento em relação a práticas educativas.

Neste sentido, o projeto, realizado com as alunas do último ano de Letras, rompe com a linearidade e fragmentação das disciplinas, articula língua e literatura, a fim de que as participantes do projeto experenciem concretamente o que propõe o pensamento complexo, que é a ruptura dos paradigmas tradicionais e reducionistas. O projeto oferece recursos para que língua e literatura espanhola sejam vividas, entendidas e compreendidas como um todo, assim como o ser humano é, um sujeito simultaneamente singular, uno e múltiplo, como ensina Morin (2011), ele não é fragmentado, ele carrega em um só corpo características individuais, sociais e de sua espécie. Para Morin, o ser humano é corpo, mente e espírito, não há como fragmentá-lo:

O ser humano é um ser racional e irracional, capaz de medida e desmedida; sujeito de afetividade intensa e instável. Sorri, ri, chora, mas sabe também conhecer com objetividade; é sério e calculista, mas também ansioso, angustiado, gozador, ébrio, extático; é um ser de violência e de ternura, de amor e de ódio; é um ser que é invadido pelo imaginário e que pode reconhecer o real; que é consciente da morte, mas que não 
pode crer nela; que secreta o mito e a magia, mas também a ciência e a filosofia; que é possuído pelos deuses e pelas ideias, mas que duvida dos deuses e critica as ideias; nutre-se dos conhecimentos comprovados mas também de ilusões e de quimeras. (MORIN, 2011, p. 53)

A partir do pensamento complexo de Morin, percebo que a epistemologia da complexidade oferece bases sólidas para enfrentar o grande desafio de todos os educadores, que é a superação do reducionismo e fragmentação do conhecimento. A complexidade é a articulação entre a unidade e a multiplicidade e não é entendida como uma teoria rígida, e tampouco possui uma metodologia própria. Exercer uma prática educativa, baseada nesse pensamento, possibilita a articulação entre os saberes, o estabelecimento de relações entre língua, cultura, arte e tecnologia durante o processo de construção do conhecimento pelo aluno.

\section{OS TEXTOS LITERÁRIOS COMO RECURSO DIDÁTICO DE E/LE.}

A leitura é uma ferramenta fundamental no processo de ensino/aprendizagem de $E / L E$, pois capacita o graduando a construir seu conhecimento com autonomia, sendo capaz de solucionar os problemas que poderão surgir em situações reais de leitura em língua estrangeira. Neste sentido, o esforço para articular a leitura de textos literários e língua espanhola em sala de aula pode ser estimulante na aquisição de uma língua estrangeira.

A literatura é um material a serviço da vida, demonstra preocupação com a condição humana, tornando-se, assim, material privilegiado para o conhecimento das diferentes posturas frente às diferentes situações e ações no mundo (VENTURI, 2010, p.5 apud Marinho et al, 2015, p.4). Ainda segundo Venturi (2010), o texto literário tem como função principal transformar o ser humano, tornando-o mais crítico e participante ativo a novas culturas. Por ser um ato social, a literatura torna-se uma fonte de ligações para a produção/apreensão de conhecimento; ela é vista como o meio ideal para desenvolver a consciência do uso da linguagem.

O texto literário também traz consigo a cultura de um povo. De acordo com Silva et. al (2015), ao utilizá-los, desenvolve-se não apenas a habilidade de leitura em um novo idioma, como também o conhecimento de uma nova cultura, da história de um povo, conhecimento esse imprescindível quando é iniciada a aquisição de um novo idioma.

O reconhecimento da importância do contexto cultural foi o que se levou a considerar a literatura como um recurso importante para o ensino de línguas. Dessa forma, Lima justifica:

[...] la imersión em uma cultura extranjera a través de la literatura puede aumentar la comprensión que los estudiantes tienen de la misma y ayudarles a desarrollar una consciencia cultural más amplia ${ }^{1}$ (LIMA, 1998, p.73).

\footnotetext{
${ }^{1}$ Tradução: A imersão em uma cultura estrangeira, através da literatura, pode aumentar a compreensão que os estudantes têm da mesma, e pode ajudá-los a desenvolver uma consciência cultural maior.
} 
Por meio da literatura, é possível integrar várias destrezas e conteúdos. A partir dessa proposição, o objetivo do projeto proposto às alunas é a aquisição e a prática das destrezas comunicativas, bem como pesquisar e vivenciar o espanhol em um contexto cultural, histórico e, principalmente, literário. Por se tratar de alunas que serão futuras professoras, refletir e articular a língua espanhola em um contexto maior é desenvolver a formação linguístico-comunicativa como um todo.

Passo agora para a próxima seção, exemplificando com mais profundidade como a literatura e língua espanhola foram articuladas.

\section{TUS OJOS EN LA LITERATURA}

A preocupação de incentivar as graduandas a entenderem a relevância do texto literário como recurso didático e apresentar a elas infinitas possibilidades de se encantar e reconhecer a literatura como esteio no processo de aquisição de uma língua adicional foi a motivação inicial para a criação do projeto. Para salientar essa ideia, Travaglia (2010 p.38) destaca que "a literatura é o que há de mais livre, mais forte e, por que não dizer, de mais belo de tudo o que se pode fazer com a língua".

O projeto foi realizado com as alunas do $6^{\circ}$ semestre do curso de Letras/Espanhol em um Centro Universitário Municipal no interior de São Paulo, na disciplina Literatura Espanhola e Hispano-Americana. A ideia do projeto foi concebida durante estudos realizados sobre novas perspectivas e reformas no processo educativo. Por isso, por meio das leituras realizadas por mim, percebi que é necessário se preocupar e compreender as concepções de aprendizagem que favoreçam, segundo Machado (2014, p.220), "a reintegração do meio ambiente à consciência do ser humano, ou melhor, à dinâmica da vida".

Como notava a dificuldade de as alunas perceberem língua e literatura espanhola em um contexto incomum, a proposta foi que elas articulassem as duas disciplinas e saíssem do reducionismo e fragmentação que permanecia entre as duas disciplinas. Por meio do projeto, as alunas puderam perceber o texto literário com o seu próprio olhar.

Widdowson (1984) defende a eficácia do uso de textos literários nas aulas de língua estrangeira, afirmando que o professor não deve dar, diretamente, a sua interpretação do texto. Ao contrário, deve estimular o aluno para que ele mesmo interprete-o, e isto é o que foi colocado em ação por meio do projeto.

A disciplina dispunha de uma carga horária um pouco reduzida, 1 h30 (um hora e trinta minutos) por semana, por isso, no momento do planejamento, isso foi levado em consideração. O projeto, teve a duração de 1 (um) mês e se organizou da seguinte maneira: 


\begin{tabular}{l|l}
\hline Aula 1 & $\begin{array}{l}\text { Apresentação do projeto e das obras - Tus ojos en la } \\
\text { literatura - Ressignificando a obra. }\end{array}$ \\
\hline Aula 2 & Como realizar uma fotonovela? \\
\hline Aula 3 & Elaborando e praticando. \\
\hline Aula 4 & Apresentação das fotonovelas. (Entrega do relato) \\
\hline Aula 5 & Entrega do questionário (Discussão) \\
\hline
\end{tabular}

Quadro 1 - Cronograma do desenvolvimento - Fonte: autoria própria

Como o número de estudantes dessa turma era bem reduzido, (somente 5 alunas), elas se organizaram em dois grupos, sendo uma dupla e um trio. Na aula 1, foram apresentadas as duas obras, seus autores e o contexto literário em que eles e obras se apresentam. Representando a literatura espanhola, La Gitanilla, de Cervantes, já era uma obra conhecida do grupo, porque o autor já havia sido estudado anteriormente, porém a obra não havia sido lida até o momento da proposta do projeto. A segunda obra pertence à literatura hispano-americana, Veinte poemas de amor y una canción desesperada de Pablo Neruda, representou uma oportunidade de as alunas aprofundarem os estudos sobre as obras, bem como estilo e características literárias de Neruda.

Tendo em vista o potencial das tecnologias e o desejo de tornar a aula mais instigante, foram utilizados vários recursos audiovisuais para apresentação e explicação do projeto, além de as alunas conhecerem de uma maneira dinâmicas cada um dos autores e as obras. Neste momento, várias habilidades que contribuem para sua formação linguística foram trabalhadas, entre elas se destacam as habilidades oral e auditiva.

Na aula 2, Como realizar uma fotonovela?, os grupos já estavam definidos e as alunas já haviam se familiarizado com a obra proposta, no entanto ainda não sabiam, ao certo, como poderiam elaborar uma fotonovela digital e como realmente era sua composição e estilo. Foi feita uma introdução, por meio de slides e vídeos, informando-as de que, no Brasil, as fotonovelas tiveram um mercado cativo por mais de 25 anos, entre os anos 1950 e 70, representando a ideia de uma imprensa popular feminina, com milhões de leitores de histórias publicadas em revistas com grande circulação nacional. Todas as informações fornecidas com o histórico, curiosidades das fotonovelas foram pesquisados por mim, em sites e portais educacionais. Depois de terem sido apresentadas ao gênero fotonovela e suas especificidades (tema, forma, composição e estilo), iniciamos um processo de reflexão sobre a flexibilidade deste gênero nos dias atuais e a possibilidade de ressignificá-lo.

Como foi abordado em seção anterior, o gênero é essencialmente flexível e variável, assim como a linguagem. A fotonovela possui suas especificidades, seu tempo e lugar histórico, contudo, como a língua varia, também os gêneros variam.

Por meio da construção da fotonovela digital, as alunas ressignificaram as obras segundo o olhar delas, transpondo a linguagem original dos livros, como em Veinte poemas de amor y una 
canción desesperada, a linguagem poética transformou-se em prosa, e o livro La Gitanilla, com um estilo de narrativa, também se adequou ao estilo e forma da fotonovela.

O aparato tecnológico para a composição da fotonovela não foi delimitado, cada grupo escolheria o recurso que melhor se adequasse à produção da atividade. Contudo, no momento em que foi sugerida a versão digital da fotonovela, foi notada uma insegurança por parte dos dois grupos, pelo fato de não saberem ao certo que recurso tecnológico utilizar para desenvolver o projeto.

Para a elaboração da fotonovela, foi necessária uma leitura minuciosa de cada obra, já que, no momento da construção da fotonovela, o grupo deveria concebê-la observando seus pontos relevantes para que não houvesse a perda do espírito original da obra, ou seja, que captassem sua mensagem central e não fugissem do tema.

A proposta da aula 3, Elaborando e praticando, foi o momento de organizarem e produzirem a fotonovela. Nessa aula, foi dada a oportunidade às alunas, para que tirassem dúvidas no momento da escrita do texto em espanhol. Como docente, participei das fases da execução da fotonovela na intenção de contribuir na formação linguística de cada uma. Concordando com esta ideia, Moraes sugere:

Precisamos de um docente capaz de participar, sempre que necessário, de trabalhos em grupo, com capacidade para refletir criticamente sobre sua prática e de levar os seus alunos a refletirem sobre suas ações, sobre seus erros e acertos. (MORAES, p. 179)

É importante que o docente atue no ambiente de aprendizagem. Somente assim perceberá o que precisa ser modificado, refletido ou reconstruído na sua prática cotidiana.

Nas seguintes seções, passo a relatar e interpretar as fotonovelas apresentadas, bem como os relatos e questionários respondidos pelas alunas, que propuseram identificar a articulação de língua e literatura dentro de um contexto incomum ao longo das aulas.

\section{INTERPRETANDO AS DESCOBERTAS}

$\mathrm{Na}$ aula 4, foram então apresentadas as fotonovelas elaboradas pelos dois grupos. A apresentação foi realizada em espanhol e cada grupo comentou a história do livro, relatando a maneira pela qual as fotonovelas foram elaboradas, bem como as experiências vividas durante todo o processo de construção delas.

Foi entregue também, no dia da apresentação das fotonovelas, um relato escrito de cada grupo, sobre o processo de construção da fotonovela e um questionário respondido individualmente em forma de texto escrito. As perguntas exploravam as vivências que as estudantes experimentaram durante toda a produção da fotonovela, como por exemplo: Quais foram suas dificuldades no projeto? Como as resolveu? $\mathrm{O}$ que o desenvolvimento desse projeto acrescentou ao seu conhecimento, tratando-se de língua espanhola? 
Foram, no total, 16 (dezesseis) perguntas que buscavam levar à reflexão sobre os possíveis benefícios que o projeto proporcionou à vida acadêmica de cada uma das alunas, especialmente, o desenvolvimento linguístico e literário. Todas as questões do questionário podem ser encontradas no apêndice.

Por meio do relato e do questionário coletados, foi possível observar que para elas a confecção da fotonovela foi um desafio, porém sentiram que a atividade ampliou seus conhecimentos no âmbito linguístico e literário.

Para melhor exemplificar, será interpretado o questionário e trechos do relato do grupo que confeccionou "La Gitanilla", posteriormente serão expostas as vivências do grupo que elaborou "Veinte poemas de amor y una canción desesperda".

\title{
6.1 La Gitanilla
}

Segue o primeiro trecho em que é identificado um estranhamento e insegurança no momento que foi proposta a atividade:

\begin{abstract}
Assim que fomos anunciadas que teríamos que produzir uma fotonovela de um livro espanhol, ficamos aflitas e muito pensativas no primeiro momento. Pois sabíamos apenas o essencial da obra "La Gitanilla" de Miguel de Cervantes, porém não conhecíamos os detalhes da obra. (Grupo La Gitanilla)
\end{abstract}

Nota-se, pelos relatos, que, no momento da proposta da produção da fotonovela, surgiram várias dúvidas e incertezas em relação a sua elaboração, contudo percebe-se também, pelos relatos, que ao longo das aulas, as estudantes entenderam e se organizaram para a execução da atividade, como ilustra o excerto a seguir:

Após algumas conversas e instruções de como elaborar a fotonovela, dividimos um período de leitura entre nosso grupo, onde cada uma ficou responsável pelo livro durante uma semana sendo possível a iniciação de nosso trabalho.

Ficou evidenciado que a internet foi um recurso de grande valia para que os grupos construíssem suas ideias, uma prova de que a inserção das tecnologias digitais já estão presentes no universo social e educacional dos graduandos. Segundo Zacharias (2016), o uso das tecnologias digitais na vida cotidiana tem causado mudanças consideráveis e rápidas nas formas de interação e comunicação das pessoas. Segue um trecho do relato do grupo La Gitanilla que evidencia esse fato:

Posteriormente, nos reunimos pessoalmente esclarecendo dúvidas sobre algumas palavras e seus significados. Logo em seguida, pesquisamos alguns resumos e análises na internet para nos auxiliar no entendimento da história para que realizássemos a adaptação. Através de nossos estudos, compreendemos o todo da narração partindo para a elaboração do projeto. (grifo nosso) 
A obra "La Gitanilla" é uma novela e tem como característica o texto narrativo, ao transpor esse gênero para o gênero fotonovela, o grupo continuou adotando a narração, porém fazendo algumas modificações e adaptações na linguagem para melhor situar sua fotonovela.

Seguem, agora, imagens da fotonovela "La Gitanilla" e como elas deram início a sua história:
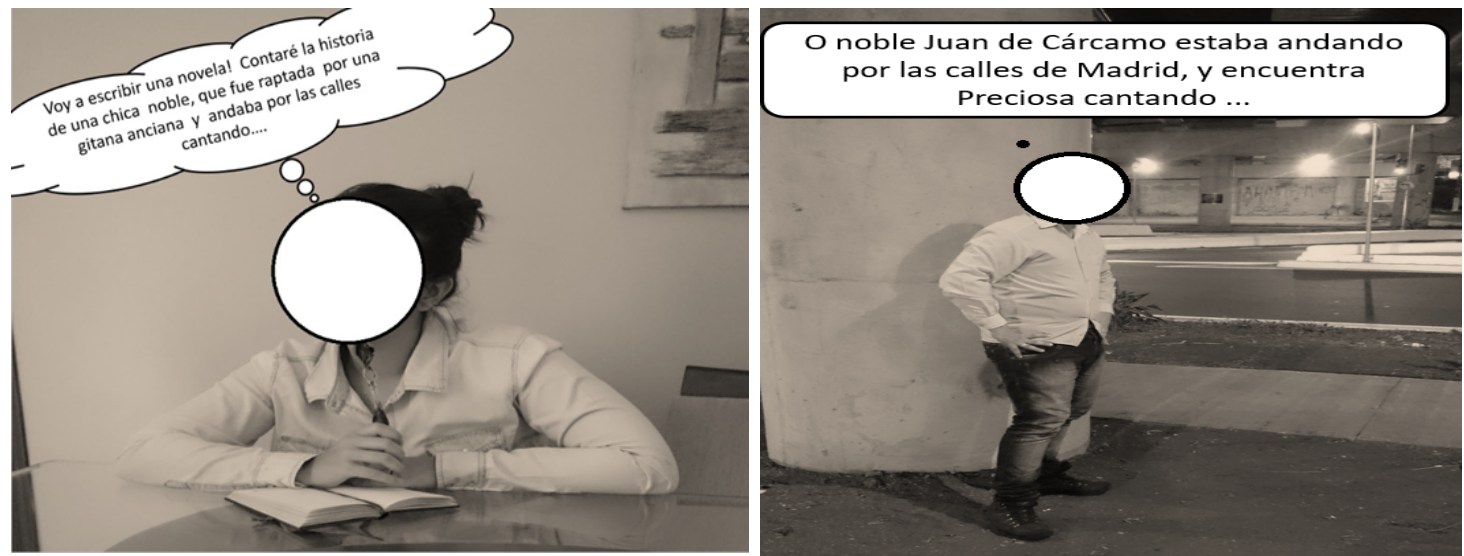

Figuras 1e 2 - Início fotonovela, La Gitanilla

Para dar início à fotonovela, uma das alunas encenou uma das autoras da história e a partir disso elaboraram uma narrativa contendo os principais fatos da obra. O grupo conseguiu transpor a novela para um linguagem e cenário mais atuais e em forma de diálogo, fazendo com que desse mais fluidez para a narrativa. Seguem mais imagens da fotonovela "La Gitanilla" para melhor entendimento e exemplificação:
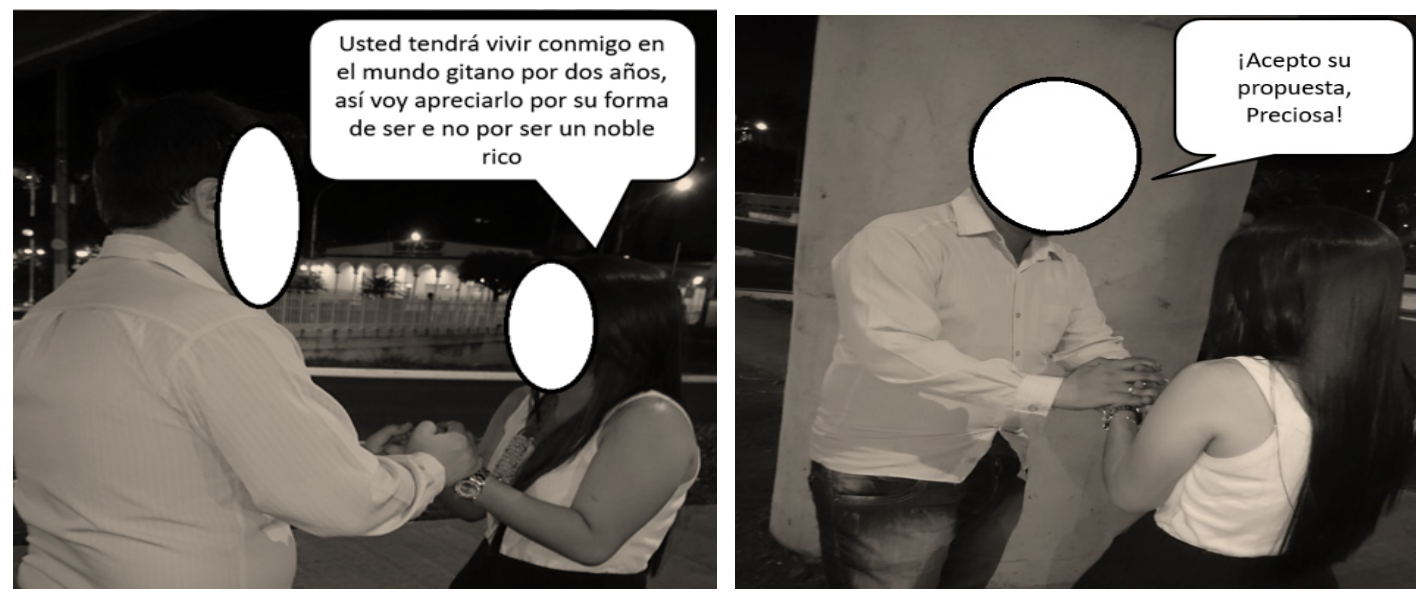

Figuras 3 e 4 - Narrativa da fotonovela

Fica, assim, evidenciada a ruptura da linearidade proposta pelo pensamento complexo. 0 grupo elaborou um texto por meio do qual conseguiram protagonizar suas autoras, sem perder o sentido e o tema central da obra original. A história continuou sendo a mesma, no entanto o grupo atingiu uma maior autonomia para desenvolver sua redação, sem copiar integralmente o texto da obra original. 
Seguimos agora com alguns trechos das respostas advindas do questionário do grupo $L a$ Gitanilla com suas descobertas e vivências ${ }^{2}$ :

Com certeza houve imersão na língua espanhola. Acredito que a maior gama de vocabulário que temos são os livros, a cada nova leitura conhecemos novas palavras. $E$ nessa leitura não foi diferente, conheci novos vocábulos e novas expressões (Texto Aluna A).

Oferecer atividades que envolvam oportunidade de leitura literária e cultura é propor ao estudante imergir no universo da língua estrangeira como um todo. 0 esforço no intento de articular a leitura de textos literários em sala de aula pode ser estimulante, se aliados a atividades dadas para ensinar estruturas gramaticais e vocabulário, aprendizagem essencial para o estudante conquistar autonomia na língua adicional. É o que se comprova no relato de outra estudante do grupo La Gitanilla:

Estivemos por dias em contato direto com a língua espanhola, para a realização do trabalho, assim, aumentamos nosso vocabulário com novas palavras e expressões (Texto Aluna B).

Por meio do relato acima, fica claro que o texto literário tem muito a oferecer, uma vez que desenvolve a compreensão leitora, linguística e é também um meio de difusão cultural, pois através dele o estudante entra em contato com a cultura da língua que se propõe a aprender:

O trabalho me fez refletir bastante sobre a língua espanhola, e ao desenvolvê-lo comtemplei o enriquecimento que a construção de cada detalhe me proporcionou. $A$ obra, fez com que eu mudasse minha visão da literatura espanhola, aprendi a apreciar de uma forma diferente os livros literários, principalmente os quais se parecem com "La Gitanilla" (Texto Aluna C).

Cosson (2012) sugere que quanto mais os alunos são envolvidos no processo de aprendizagem através da leitura, mais independentes e providos de capacidade linguística serão. Temos como exemplo o trecho do relato de uma das participantes:

A satisfação de produzir algo que de fato sensibilizou o grupo de um modo geral, é muito grande, trabalhamos motivadas a ver o resultado final e nos divertimos muito durante $o$ processo, principalmente durante a fotografias, feitas por nós mesmas, para acrescentar ao trabalho. Foi um trabalho incrivel (Texto Aluna B - grifos próprios).

Por meio do projeto, as estudantes puderam refletir sobre sua própria formação no futuro, reconheceram que diferentes práticas docentes adotadas em aula contribuem para a formação linguística e cultural do aprendiz de língua estrangeira. Isto se evidencia no relato da aluna A:

\footnotetext{
${ }^{2}$ No presente artigo, os nomes das alunas participantes da pesquisa serão trocados por A, B, C (integrantes do grupo La Gitanilla e D e E (integrantes do grupo Veinte Poemas de amor y una canción desesperada).
} 
Como professora vou procurar sempre levar a literatura para as aulas de língua espanhola. Acredito que chame mais atenção dos alunos, ajudando na interpretação de texto e aumentando cada vez mais o vocabulário dos alunos. E para conhecer e aprender uma determinada língua, é essencial que conheça sua cultura (Texto Aluna A).

\subsection{Veinte poemas de amor y una canción desesperada}

Diferente do grupo "La Gitanilla", o grupo que elaborou a fotonovela de Pablo Neruda, encontrou um maior desafio em transpor o gênero poesia para uma narrativa. Por isso, se colocaram no lugar do autor principal - Pablo Neruda - e criaram uma história na qual elas mesmas eram as autoras e buscavam inspiração para escrever um poema. Segue o excerto do relato da participante:

Pensando em tudo isso, nos questionamos se seria possível fazer do poema: "Puedo escribir los versos más tristes esta noche", uma narrativa, ou seja, fazer uma transferência/troca de gênero. E assim, o fizemos, uma interpretação do poema como se nós fossemos as autoras do livro e estivéssemos escrevendo aquele poema, o último poema do livro. Com a leitura do texto, identificamos e imaginamos o cenário para nossa atuação. E o apresentamos como narrativa. (Aluna E)

Segue o início da fotonovela e os recursos adotados pelas participantes para transpor o livro de poesia para o gênero fotonovela:
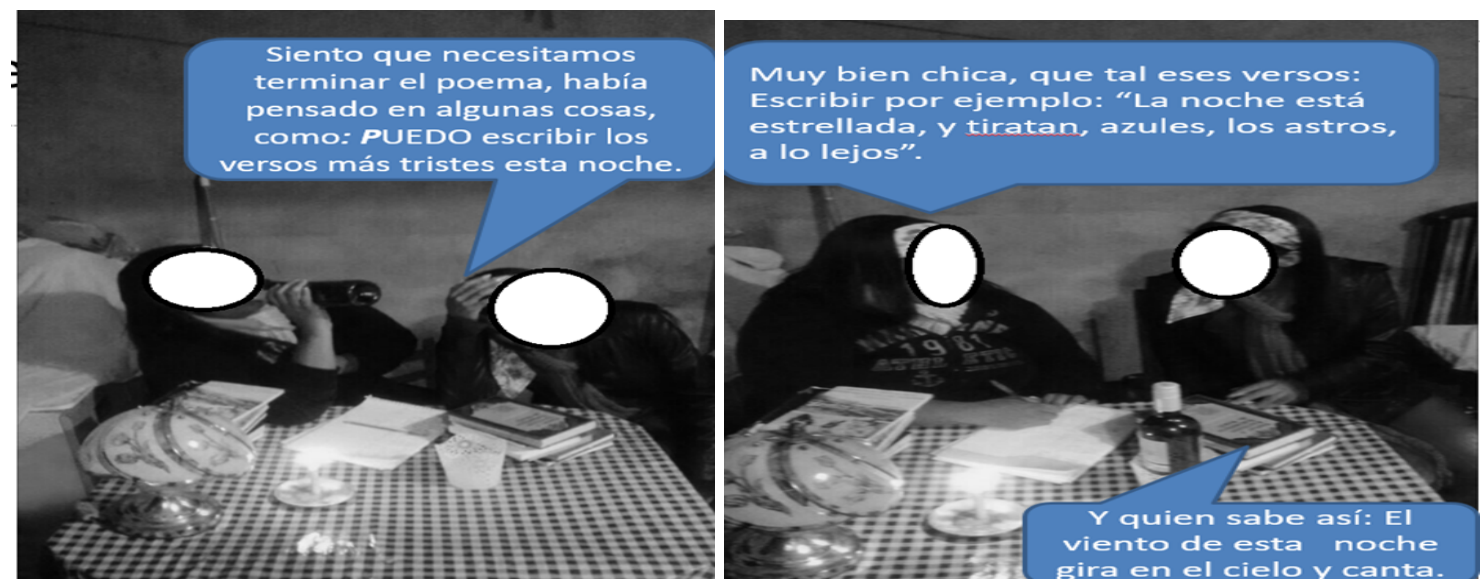

Figuras 5 e 6 - Inicio fotonovela, Veinte Poemas de amor y una canción desesperada

Nota-se que, ao mesmo tempo em que modificam a forma de apresentação do texto poético para a forma composicional fotonovela, não alteram a linguagem do poema, ou seja, não modificam o texto original para a elaboração de sua fotonovela. Elas adequam o texto, para que esse caiba na composição da fotonovela.

É importante reconhecer, segundo Moraes (2010), que a formação docente deve ser pensada como um todo, articulada aos diferentes processos e dimensões envolvidas. 0 projeto 
realizado tentou romper com pensamento tradicional e buscou motivar as alunas a uma docência transdisciplinar e complexa, que deve ser sempre algo aberto e criativo, desenvolvido em um espaço contínuo de reflexão, que une diversas áreas do saber em um contexto incomum.

Esse contanto com a literatura possibilita um aprendizado significativo, como professores de espanhol, não devemos vincular nossas aulas apenas ao ensino da gramática. Como docentes, devemos suscitar nos nossos aprendizes atitudes reflexivas, temos que inserilos num contexto abrangente, para que o mesmo veja coerência de determinado conteúdo com sua realidade(Texto Aluna E) [sic].

Projetos como estes, segundo Cosson (2007), tornam o aprendiz mais confiante como leitores e ampliam sua compreensão vocabular e, principalmente, experimentam novos sentidos e interpretações. Isto se comprova com o excerto abaixo:

Esse trabalho acima de tudo possibilitou uma imersão na língua espanhola, através do conhecimento de novos vocabulários, até então, algumas palavras eram desconhecidas por nós, houve uma fusão da língua com a cultura [...] (Texto Aluna E).

Segundo Pedraza Jiménez (1996, p.61), o processo de aprendizagem de uma língua estrangeira ocorre somente quando existe o uso da língua real, e esta pode ser apresentada aos alunos de duas maneiras: por meio da comunicação espontânea com nativos - o que, muitas vezes, só é possibilitado em um estágio avançado de aprendizagem e em um lugar em que se fale o idioma que se pretende adquirir, ou por meio da leitura de textos literários - não pela literatura em si mesma, mas porque os textos literários são realizações efetivas da virtualidade de uma língua. Pela literatura, segundo o autor, o aprendiz se aproxima da realidade que deve conhecer e ao mesmo tempo facilita a assimilação cultural. Destaca também que a literatura deve estar presente em todos os seus níveis, desde o inicial até níveis avançados despertando, como consequência, o amor pelos textos literários. Por meio do excerto abaixo, escrito pela graduanda, uma das produtoras da fotonovela de Pablo Neruda, identificamos esse pensamento:

O trabalho contribuiu e despertou meu interesse pela literatura espanhola, possibilitando enxergar e fazer novas interpretações do mundo literário (Texto aluna D) [grifos nossos].

O excerto acima revela que o texto literário quando trabalhado por meio de propostas coerentes, envolvidas com todo aspecto lúdico, não só atinge o interesse do aluno, como também proporciona ao aprendiz perceber e relacionar as nuances literárias, ao mesmo tempo em que explora as possibilidades a respeito da língua-alvo.

\section{CONSIDERAÇÕES FINAIS}

O pensamento complexo integra os diversos modos de pensar, opõe-se aos mecanismos reducionistas e leva em conta as influências internas e externas aos sistemas e a literatura, por sua vez, é uma manifestação inerente ao homem, independentemente do tempo e da época. 
Essa ideia vai ao encontro do pensamento de Cândido (2012), que defende que o ser humano é incapaz de viver sem a presença de alguma espécie de fabulação, ou seja, cada grupo social projeta a sua manifestação ficcional, poética, dramática, conforme suas crenças.

Por meio deste estudo, foi possível interpretar e reconhecer que quando a literatura está permeando a construção dos saberes, ou melhor, quando a articulação entre língua e literatura são escolhidas como recurso de aprendizagem de língua espanhola, as experiências vivenciadas e construídas pelos alunos vão além do desenvolvimento linguístico, toca-se a cultura, a história, e leva o estudante a compreender a língua como um universo de possibilidades de construção de conhecimento. Por meio dos relatos escritos pelas participantes, foi possível reconhecer a relevância do tentar mudar, sair do reducionismo e incentivar a construção do conhecimento de forma contextualizada, visando o todo e as partes.

\section{REFERÊNCIAS}

ALMEIDA, C.R.S. de. É possível exercer uma prática educativa baseada no pensamento complexo? In: MORAES, M.C; SUANNO, J.H. (Orgs.). O pensar complexo na educação: sustentabilidade, transdisciplinaridade e criatividade. Rio de Janeiro: Wak Editora, 2014.

BAKHTIN, M. Estética da criação verbal. São Paulo: Martins Fontes, 1997.

BRAIT, B.; PISTORI, M.H.C. A produtividade do conceito de gênero em Bakhtin e o Círculo. Alfa: Revista de Linguística (UNESP. Online), v. 56, p. 371-401, 2012.

BALDASSO, Vagner. Histórico Sobre as Fotonovelas. Disponível em: http://asfotonovelas.blogspot.com.br/p/as-fotonovelas-uma-historia-de-ascensao.html. Acesso em: 02 de mai. 2018.

BEHRENS, M.A.; ENS, R.T. (Orgs.). Complexidade e Transdisciplinaridade: novas perspectivas teóricas e práticas para a formação de professores. Curitiba: Appris, 2015.

BEZERRA, M.A. (Org.). Gêneros Textuais \& ensino. RJ: Lucerna, 2010.

. Gêneros textuais: configuração, dinamicidade e circulação. In: KARWOSKI, A.M; GAYDECZKA, K.S.B; BRITO, K.S. Gêneros textuais: reflexões e ensino. São Paulo: Parábola, 2011.

CANDIDO, A. O direito à literatura. In: LIMA, A. de (Org.). O direito à literatura. Recife: Ed. Universitária da UFPE, 2012.

CARDOSO, R; CARDOSO, C. Ler para conhecer: A literatura como processo didático nas aulas de E/LE. In: DUTRA, E.O. de; SIMIONI, T. (Orgs.). O ensino do espanhol: caminhos e perspectivas. Campinas: Pontes, 2017. p.213-234.

COELHO, P.P.F; TONHATI, P.P.F. O uso do Instagram nas aulas de língua espanhola: ressignificando o cartão postal sob a luz da complexidade. In: vi simpósio de educação e iii encontro internacional de políticas públicas em educação, 2017, Franca. Anais ... Franca: Uni-FACEF; Unesp, 2017. p. 1342-1351.

COSSON, R. Letramento Literário, teoria e prática. São Paulo: Editora Contexto, 2007.

MARCUSHI, L.A. Gêneros textuais: definição e funcionalidade. In: DIONÍSIO, A.P; MACHADO, A.R; BEZERRA, M.A. Gêneros textuais e ensino. São Paulo: Parábola Editorial, 2010. 
MORAES. C.M. Ecologia dos saberes: complexidade, transdisciplinaridade e educação: novos fundamentos para iluminar novas práticas educacionais. São Paulo: Antakarana/WHH Willins Harman House, 2008.

. Complexidade e transdisciplinaridade na formação docente. In: NAVAS, J.M.B. (Orgs.). Complexidade e transdisciplinaridade em educação: teoria e prática docente. Rio de Janeiro: Wak Editora, 2010.

MORIN, E. Introdução ao pensamento complexo. Tradução Eliane Lisboa. 4.ed. Porto Alegre: Sulina, 2011.

Os sete saberes necessários à educação do futuro. Disponível em: http://portal.mec.gov.br/seb/arquivos/pdf/EdgarMorin.pdf. Acesso em: 03 de mar. de 2018.

PEDRAZA JIMÉNEZ, Felipe B. La literatura en la clase de español para extranjeros. Disponível em: http://cvc.cervantes.es/ensenancanza/biblioteca_ele/asele/pdf/07/07_0057.pdf. Acesso em: 05 de mai. de 2018.

PETRAGLIA, I. O processo de produção do conhecimento: complexidade e transdisciplinaridade. In:

SÁ, R. A de. Em busca de uma pedagogia complexa. In: BEHRENS, M.A.; ENS, R.T (Orgs.). Complexidade e Transdisciplinaridade: novas perspectivas teóricas e práticas para a formação de professores. Curitiba: Appris, 2015.

SILVA, Wanderley da. $\mathbf{O}$ uso do texto literário como recurso didático nas aulas de espanhol como língua estrangeira - e/le no ensino médio de escolas públicas. Disponível em: http://www.editorarealize.com.br/revistas/setepe/trabalhos/Modalidade_1datahora_29_0 9_2014_10_17_16_idinscrito_917_700f626e4c0814a8c596aba9c64c750e.pdf. Acesso em: 02 de mai. 2018.

VENTURI, M. A. A Leitura Do Texto Literário No Ensino Fundamental E Médio. Disponível em: http://www.fflch.usp.br/dlcv/lport/pdf/slp03/21.pdf. Acesso em: 05 de jul. de 2014.

WIDDOWSON, H. G. The use of literature. In: Explorations in applied linguistics

2. Oxford: Oxford University Press, 1984.

ZACHARIAS, V.R.C de Letramento digital: desafios e possibilidades para o ensino. In: COSCARELLI, C.V. (Org.). Tecnologia para aprender. São Paulo: Parábola, 2016. p. 15-26.

JOUINI, Khemais. El texto literario en la clase de español como lengua extranjera: propuestas y modelos de uso Íkala. Revista de lenguaje y cultura, Medellín, vol. 13, p. 121-159, dez.2008.

\section{APÊNDICE}

Curso: Letras

Disciplina: Literatura Espanhola e Hispano-americana

$6^{\circ}$ semestre 
Atividade - "Tus ojos en la literatura" Nota:

Aluno: $n^{\circ}:$

1. O que sentiram ao ler o livro?

2. O que sentiram ao desenvolverem a fotonovela?

3.Quais foram suas dificuldades no projeto? Como as resolveu?

4. Houve momentos de satisfação e alegria? Descreva-os

5. Houve momentos de desânimo? Quando? Descreva

6. Você sentiu que houve uma imersão na língua espanhola? Dê exemplo

7. Você sentiu que houve uma imersão na literatura espanhola? Dê exemplo

8. Você leu resumos, adaptações para realizar o projeto (teatro e fotonovela)?

9. Você leu a obra toda em espanhol ou também visitou alguma tradução dela. Explique.

10. Como futura professora, você acredita que vale a pena "viajar em sala de aula" por meio da literatura? Justifique.

11. Como futura professora, como você traria a literatura para a aula de língua espanhola?

12. Como foi passar a obra para o gênero "teatro" para a apresentação? Explique como seu grupo fez e organizou essa etapa do projeto.

13.0 que o desenvolvimento desse projeto acrescentou ao seu conhecimento de tratando-se de língua espanhola?

14. O que o desenvolvimento desse projeto acrescentou ao seu conhecimento de tratando-se de literatura espanhola?

15. Você aprendeu algo com suas colegas, esse convívio foi favorável ao projeto, fez diferença? O quê? Quando e como isso aconteceu? Em caso negativo, justifique por que isso não aconteceu.

16. Você acredita que o contexto influenciou sua aprendizagem? Explique sua resposta.

17. Você acredita que o projeto desenvolvido pode ser entendido como um projeto de formação de professores? Por quê? Explique. 